\title{
The design, development and evaluation of a self-instructional module for nursing practice standards
}

\author{
June Anonson, Mary Ellen Walker \\ University of Saskatchewan, Prince Albert Campus, Prince Albert, Canada \\ Email: june.anonson@usask.ca
}

Received 11 September 2013; revised 25 October 2013; accepted 8 November 2013

Copyright (C 2013 June Anonson, Mary Ellen Walker. This is an open access article distributed under the Creative Commons Attribution License, which permits unrestricted use, distribution, and reproduction in any medium, provided the original work is properly cited.

\begin{abstract}
The purpose of this research was to improve nursing professionals' understanding of the important link to safe, competent, and ethical practices that Nursing Practice Standards (NPS) serve. This research on NPS may improve the scope and comprehensiveness by which the Standards are integrated with clinical, educational, administrative, and research-based nursing practices. This research was unique in that it includes nurses in developing NPS. The method by which this study was done involved sixteen practicing nurses and seven instructional design experts from Alberta, Canada participating in designing, developing, and evaluating a NPS module. Nursing practice standards are a vital aspect of performing safe, efficient and effective patient care. The manner in which Nursing Standard Practices are presented and taught will directly influence a nurse's ability to understand the value of NPS and successfully incorporate NPS into practice.
\end{abstract}

Keywords: Nursing Practice Standards; Evidence Based Practice; Nursing Standards of Care

\section{INTRODUCTION}

As practicing professionals, nurses are expected to comply with certain rules or standards. It is not clear whether the general population of nurses in the province of Alberta, Canada are aware of these standards, and if they are, the standards are being implemented. This article intends to provide an extensive literature review on the nursing practice standards (NPS) in Canada and justification for their existence. This article also intends to assist the practicing nurse in becoming more familiar with NPS, as they are a practical and easily accessible method of selfstudy. The overall purpose of the study was to design, develop and evaluate a self-study module for NPS.

\section{SIGNIFICANCE}

The nursing profession relies on practice standards to provide guidance, define direction, and aid in professional accountability as shown in numerous studies [1-4]. However, these studies do not address specific tools that the nurses can use to increase their knowledge of the practice standards. Questions and concerns related to NPS had increased "to 28 percent from 18 percent of all consultations by the College and Association of Registered Nurses of Alberta (CARNA)" (p. 8) [5]. Registered nurses (RNs) and employers have shown their need for increased direction for "issues that directly or indirectly affected delivery of safe, competent and ethical nursing care” (p. 8) [5].

\section{BACKGROUND}

\subsection{Nursing Practice Standards}

All professions have certain rules and regulations on which their practice is built, and nursing is no exception. There have been vast amounts of information written about NPS. Smith-Marker [4] refer to standards as the "building blocks of professional practice" (p. 1) and describe them as a "written value statement that defines a level of performance (in the staff) or a set of conditions (in the system or the patient) determined to be acceptable by some authority" (p. 3).

"Standards are essential to the nursing profession because they define unequivocally what quality nursing care is while providing specific criteria that can be used to determine whether quality care has been provided" (p. 7) [6]. Standards are meant not only to accomplish patient care outcomes related to specific patient needs [3]. NPS are also meant to evaluate the nursing processes which nurses use to care for patients [2]. However, stan- 
dards additionally "define the excellence desired in patient care and serve as the structure from which the job descriptions and performance evaluations are developed" (p. 9) [2].

Practice standards "focus on the functions of the provider of care (the nurse) and are written about the nursing process" (p. 23) [7], differentiating them from a standard of care which "focuses on the recipient of care (the patient)" (p. 23). Practice standards are also known as professional standards. NPS are supposed to assist nurses in providing quality care. However, practice standards are only useful within clinical practice if nurses are able to understand them, and if the standards are clearly applicable to a broad range of procedures, tasks, and situations [8].

There are models of NPS for many nursing specialities in most Canadian provinces and American states. Each group has created these standards to reflect its unique area and delivery of care. In most models, the standards relate to four areas or dimensions in order to achieve desired outcomes: assessment, planning, implementation, and evaluation [2]. Mason [6] explains.

As a meaningful, valid definition of nursing care, a nursing standard describes what should be done and how the client will benefit from good nursing care. Well-developed standards not only identify the primary responsibilities of nurses, but also define the quality of the administration of these responsibilities (p. 5).

Many provincial models reflect three frames of reference: structure/content, process, and outcome [4,6,9]. According to Jerning and Young [2].

Standards can be established to appraise care... The nursing organization or structure is usually evaluated according to structure standards, the activities or delivery of care are evaluated by process standards, and the patient's status is evaluated by outcome standards. But all three types of standards are interrelated and can be used to evaluate various aspects in a nursing service (p. 10).

This monitoring of the practice standards is a vital ongoing process for the success of their implementation and credibility.

All NPS are formalized in writing and define nursing practice and nursing duties, both clinical or administrative. Written standards promote "acceptable levels of patient care" (p. 3) [4]. They include general system operations that serve as a base for other programs, such as orientation, quality assurance, and performance appraisals. Smith-Marker [4] asserts that NPS provide "definition to nursing care, control obstacles that impede care, and delineate professional accountability” (p. 3).

Standards in professions can be used to help produce and assess a certain quality of service. Mason [6] states that the actual quality of nursing care, defined by a standard, can be evaluated: "the standards of practice tradi- tionally accepted as part of the basic content of the various health professions have not been adequate to ensure that individuals, hospitals, and practitioners provide safe and effective service to patients” (p. 10) [1]. This may be partially explained because professional standards are not always complied by health professionals.

The factors that influence the success of implementation of NPS are as diverse as the areas of expertise in the profession. The standards must be reviewed by experts in various areas of nursing who comprehend the nursing scope of practice as it relates to a particular speciality [3]. NPS need to be reviewed and updated regularly in order to ensure they are "explicit and therefore meaningful to the nurse who must actually implement [them]" (p. 7) [6].

Nurses need to understand the reason for NPS and be committed to providing nursing care based on those standards in order for NPS to be successfully integrated into daily patient care [3]. Nurses must believe that they are an intricate part of the NPS, have some ownership of NPS, and be committed to realizing the objectives of the NPS $[1,3,4,6]$. Cantor [1] states that "to assure the delivery of safe nursing care based on desired and expected quality expectations, the integration of the demands of these multiple sources at the practice level is a vital link in the development and use of written standards to guide the practice of nurses" (p. 12). Therefore, because "many nurses do not realize how standards of practice develop", or the extent to which they practice the standards they say they espouse, NPS should be applicable, easy to understand, and based on sound principles. This will allow nurses to have confidence in NPS for their own practice.

One of the first obstacles to the implementation of NPS is lack of time. Nurses are being given more responsibilities, with less time to fulfill them. Smith-Marker [4] agrees that nurses believe NPS are too time consuming. NPS development is a dynamic process, so developing NPS is a trade-off. Developing NPS can help to reduce confusion, duplication, and errors of omission that will save time and benefit everyone involved - once the standards are implemented. Another obstacle is that nurses may not "buy into" the idea of NPS because "standards reduce autonomy and independent nursing judgment” (p. 4). Schroeder 3 states that, historically, NPS were rarely implemented because they typically contain unrealistic and unachievable expectations of care by the practicing nurse. The lack of relevancy deters compliance to NPS. Standards must be scrutinized for their relevancy to each situation (p. 12) [3]. Another obstacle to NPS is the potential for litigation. Although this problem has been more prevalent for nurses practicing in the USA, it is also a reality for Canadian nurses. Nurses fear that with the implementation of detailed NPS, liability, and therefore litigation, will increase for nursing professionals. However, both Smith-Marker [4] and Schroeder [3] as- 
sert that if standards are implemented, litigation should decrease. Unfortunately, there remain ambiguities in written standards, which has led to non-compliance. Because of the "economic incentives to motivate hospitals to control costs", Smith-Marker asserts that it is imperative to "define competent professional care as precisely as possible... by delineating roles and responsibilities..." (p. 9).

\subsection{Adult Learning}

Learning occurs in the cognitive, affective, and psychomotor domains [10-12]. Dickinson [10] states that the evaluative instruments for these domains are cognitivecontent tests, affective-attitude scales, and psychomotorrating scales. According to experts in this area, the content tests measure two types of memory: recall and recognition. The result of the evaluation is that learning is best achieved, for the adult learner, through the active participation or involvement of the learner [10-12]. Thus, the learner begins to have a greater appreciation for the subject matter, which is vital to the internalization and learner's ownership of it. Ultimately, the literature supports the concept that learners and their behaviour are the most important items and these should be the primary focus when considering adult education [10,11,13-15].

Three attributes of material readily learned by adults are meaningfulness, relevancy, and immediate feedback. Meaningful information-either similar to what the adult already knows, or presented in a structure which the adult can understand and relate to-enhances adult learning [10-12]. Stage-by-stage demonstrations and explanations of what is expected of the student will hasten her/ his learning of the new materials [11,12]. Reinforcement, positive or negative immediate feedback, will direct the learner and enhance learning.

Although adult learning levels tend to remain high throughout life, learning abilities may be inhibited by psychological and physiological factors. Adult learners often find themselves in conflict with new materials because of their a priori ideas. A new idea is "to admit that there is something wrong with our [the adults'] own system of ideas and beliefs" (p. 12) [12]. In addition, they face a "fear of the new, the uncertainty of pushing back boundaries and the remembrance of past learning failures or unsatisfactory experiences” (p. 34) [14]. According to Dickinson [10], adult learners are highly differentiated: this group has a wider range of knowledge, experience, age range, and learning interests than would a group of pre-adults. Adult learners see themselves as independent and have more experiences to aid the integration of new knowledge [10,12]. They also consider self-direction as essential in their learning processes [16].

Knox [17] states that because of their diversity in learning needs, adults need "more specialized educa- tional activities, materials and self-directed study arrangements in an effort to maximize responsiveness and application” (p. 30). For adults, process demonstration, case studies, and simulations provide valuable opportunities for adults to learn [10,12,15,17]. Therefore, when constructing learning materials for NPS, one must keep in mind that the materials should include realistic examples or, preferably, practical demonstrations, and that the learners should have ample opportunity to practice working with the standards on the job.

Because adults perceive themselves to be self-directed and independent, "an open instructional strategy gives the learners a more active part in directing their own learning activities” (p. 67) [10]. This is in opposition to a closed strategy - a teacher-controlled learning environment. This self-instructional strategy gives individuals the ability to learn at his or her own pace, and choose a setting, providing the learner autonomy [17]. Adult learning is more effective when the "instructor serves as a facilitator of the learning by adults rather than a transmitter of knowledge” (p. 93) [13].

The main criteria for establishing whether the course or learning materials presented to adults were effective are: 1) effectiveness, 2) appropriateness, and 3) practicality [10,14,17]. Rogers [12], lists other important criteria: “1) language is politically correct, simple, and direct; 2) objectives are written and testable and obtained by set tasks; 3) answers draw on personal experience; 4) the opportunity for feedback on the learner's answers; 5) professional quality presentation; 6) materials presented in 'timed chunks'; and 7) a course index is provided” (p. 151-152). It is also important to evaluate the learner throughout the learning process [10]. A self-study module that follows these criteria creates the optimal materials for adult learners

\section{METHODOLOGY}

The overall purpose of the study was to design, develop and evaluate a self-study module for NPS. The research sequence this study applied comes from an adaptation of the research and development cycle described by Borg and Gall [18] as a "process used to develop and validate educational products” (p. 782).

\section{DESIGN AND DEVELOPMENT}

A literature review and a needs assessment survey, completed through informal interviews of registered nurses (RNs) and individuals who were presently working or had in the past worked on NPS, indicated a need existed for education on the NPS for nurses. The literature also indicated one of the best methods to impart this information with an adult population would be through self-study. Using research from the literature review, skills to be 
learned, objectives, and learning activities were identified. Ethics review was obtained from the researcher's Education Administration Committee at the University of Alberta. Information obtained from the literature was tested and supported with a group of six RNs who had volunteered to work on the NPS to support the development of a self-study module. These volunteers were included to provide an overall retrospective-subjective view and response of the study module.

Subsequently, a self-study module was designed and developed that focused on three objectives: 1) to develop with nurses an awareness of the value of NPS on daily implementation of their nursing care, 2) to improve nursing professionals' understanding of the important link to safe, competent, and ethical practice the Standards serve, and 3) to improve the scope and comprehensiveness by which the Standards are integrated within clinical, educational, administrative, and researched-based nursing practices.

\section{EVALUATION}

Questionnaires were developed to test the module content using input from various researchers [19-23], adapting some of their material to fit this research. The questionnaire went through an extensive revision process. The initial draft of the questionnaire and module was reviewed, and preliminary field testing was done with the original six RNs. Suggestions for improvement were incorporated and the draft was reviewed again. Then, two distinct questionnaires were mailed out to the RN participants and the instructional design experts, the responses resulting in a third and final revision. The questionnaires and modules were mailed to seven volunteer RNs, who, in turn, mailed out seven more questionnaires and modules to other nurse volunteers. Upon the completion of the final draft, the North Central District of Alberta Association of Registered Nurses (AARN) assumed the responsibility of working with the publisher and monitoring distribution to provide quality control.

\section{SAMPLE}

For the purpose of this study, two discrete populations were selected. The first population included 16 RNs from various parts of Alberta, Canada who volunteered to take the study. The second population included 7 instructional design experts, also from Alberta, Canada, and presently practicing in this field of design. This population was picked from a convenience group; they were easily distinguishable by co-workers as being experts in the field and were also readily accessible by the researcher. The response rate was excellent with 93 per cent (or 14 of 15) of the RNs and 100 percent of the instructional design experts returning questionnaires.

\section{DELIMITATIONS}

This study was delimited to the population of nurses practicing in the North Central District of the Alberta Association of Registered Nurses [24]. No attempt was made to include nurses outside of this district because of the volunteer sample that agreed to participate in the study. It was also delimited to experts in instructional design who had worked previously with instructional modules.

\section{LIMITATIONS}

The data collected was descriptive of a select population and thus was not able to generalize to others (e.g., nurses returning for a refresher course that have been out of practice for several years and no longer hold a current licence in nursing).

\section{ANALYSIS}

The module evaluation questionnaire consisted of two parts: 1) the demographics portion which collects data on the participants-21 questions for the RNs and 15 questions for the design experts; and 2) the primary source of data collection for the evaluation of the self study module. The research instrument was designed to procure background information (demographics) concerning the participants, and it also asked questions that directly pertained to the module. These questions about the module were categorized into eight areas adapted from Race [22]: need, suitability of module to meet perceived need, content, physical layout, errors, bias, and completion rate. The overall assessment for each of the questions concerning the self-study module was overwhelmingly supportive; only one of the 21 was consistently non-supportive. Based on the results of this research, the module was revised and improved for a final draft.

Data from Part A revealed that all of the participants were RNs with 64.3 percent having attained an educational qualification of a BA or higher. The instructional design participants had all completed a Masters degree and 42.9 percent of these had also completed a doctorate. The highest percentage of nurses (35.7 percent) worked in the hospital setting, and most were staff nurses. Their average length of experience as an $\mathrm{RN}$ was 17.4 years. Seventy-one per cent of the nurses had worked on a committee that had focused on the some kind of NPS. The highest percentage of the design participants (42.9 percent) worked in a university setting and had responsibilities in the area of instructional design. The average length of experience of the instructional design group was 17.7 years.

Data from Part B concluded that the majority of the nurse participants, who had read the practice standards, 
were supportive of the need for further education in the area of NPS and the suitability of the self-study module. The data show that the majority of the nurses believed the module met the criteria for sequence, authenticity, timelines, appropriateness, clarity, accuracy, flexibility, and readability. The physical layout was considered acceptable, and no discernible errors were indicated by either survey group. Most participants in the study believed that the module was free of biases. However, two nurse participants indicated that some philosophical and ethical biases were present, and one design participant indicated a gender bias.

As an example of these questions/answers the following table has been included below:

Table 1 Usefulness to Different Types of Nurses.

Please rate the usefulness of this module to the following categories of nurses:

1) very useful; 2) useful; 3) some use; 4) little use; 5) no use.
a) Experienced R.N.'s;
b) New graduate nurses;
c) Student nurse;
d) Nurses engaged in remedial/refresher work.

\section{OBSERVATIONS \& RECOMMENDATIONS}

The first outcome of this study was that the endeavour was supported by professionals beyond the field of nursing. A high percentage of nurses (71 percent) had previously been involved on committees that focused on the NPS, which may mean that the information obtained in the questionnaires cannot be generalized to the whole membership of the AARN. Despite this limitation, it is recommended that 1 ) the module be completed and evaluated by the general membership, 2) future educational programs include a study on NPS, 3) further inservices on practice standards be provided to nurse leaders for subsequent coaching of staff, 4) the questionnaires from this research be adapted for other research, and 5) nursing leaders develop strategies that help staff value and implement NPS in daily practice.

\section{CONCLUSION}

“AARN Nursing Practice Standards are the benchmark for RN practice and provide RNs with guidance by representing acceptable requirements for determining the quality of nursing care a patient receives” (p. 17) [25]. As NPS are structured and defined to meet the needs of the province, they become an indispensable resource to the nurses of the region. As "health care costs have escalated disproportionately compared to the rest of the economy” [4], the field of nursing has been struggling to rise to this challenge. Currently, RNs make up an increas-
Table 1. Module’s perceived usefulness.

\begin{tabular}{ccccccccc}
\hline & \multicolumn{2}{c}{$\begin{array}{c}\text { Experienced } \\
\text { R.N. }\end{array}$} & $\begin{array}{c}\text { New } \\
\text { graduate } \\
\text { nurse }\end{array}$ & $\begin{array}{c}\text { Student } \\
\text { nurse }\end{array}$ & \multicolumn{2}{c}{$\begin{array}{c}\text { Nurse engaged in } \\
\text { refresher work }\end{array}$} \\
\cline { 2 - 9 } & $\#$ & $\%$ & $\#$ & $\%$ & $\#$ & $\%$ & $\#$ & $\%$ \\
\hline $\begin{array}{c}\text { 1) Very } \\
\text { useful }\end{array}$ & 3 & 21.4 & 7 & 50 & 8 & 57.1 & 5 & 35.7 \\
2) Useful & 5 & 35.7 & 2 & 14.3 & 2 & 14.3 & 5 & 35.7 \\
3) Some use & 2 & 14.3 & 2 & 14.3 & 1 & 7.1 & 1 & 7.1 \\
4) Little use & 1 & 7.1 & - & - & - & - & - & - \\
5) No use & 1 & 7.1 & 1 & 7.1 & 1 & 7.1 & 1 & 7.1 \\
No reply & 2 & 14.3 & 2 & 14.3 & 2 & 14.3 & 2 & 14.3 \\
Total & 14 & 100 & 14 & 100 & 14 & 100 & 14 & 100 \\
\hline
\end{tabular}

ingly larger percentage of healthcare professionals. For the sake of safe, efficient and effective patient care, it has become imperative for quality and relevant NPS to be implemented in every nurse's practice.

\section{REFERENCES}

[1] Cantor, M.M. (1978) Achieving nursing care standards: Internal and external. Nursing Resources, Inc., Wakefield.

[2] Jernigan, D.K. and Young, A.P. (1983) Standards, job descriptions, and performance evaluations for nursing practice. Appleton-Century-Crofts, Norwalk.

[3] Schroeder, P. (1991) Approaches to nursing standards. Aspen Publication, Thiensville.

[4] Smith-Marker, C. (1988) Setting standards for professional nursing: The marker model. The C.V. Mosby Company, Baltimore.

[5] Allen, D., Chassé, M., Hogg, D. and Phillipchuk, D. (2006) Latest review shows rise in calls related to nursing practice standards. Alberta RN, 62, 8-9.

[6] Mason, E. (1984) How to write meaningful nursing standards. 2nd Edition, Wiley Medical Publications, New York.

[7] Arries, E. (2006) Practice standards for quality clinical decision-making in nursing. Curationis, 29, 62-72. http://dx.doi.org/10.4102/curationis.v29i1.1052

[8] Dozier, A. (1998) Professional standards: Linking care, competence, and quality. Journal of Nursing Care Quality, 12, 22-29.

http://dx.doi.org/10.1097/00001786-199804000-00007

[9] Nicholls, M. (1977) Terminology in quality assurance. In: N. Nichols and V. Wessels, Eds., Nursing Standards and Nursing Process, Contemporary Publishers, Wakefield, 31-38.

[10] Dickinson, G. (1973) Teaching adults. New Press, Toronto. 
[11] Knox, A.B. (1977) Adult development and learning: A handbook on individual growth and competence in the adult years. Jossey-Bass, San Francisco.

[12] Rogers, J. (1989) Adults learning. 3rd Edition, Open University Press, Philadelphia.

[13] Edwards, R. (2001) Meeting individual learner needs: Power, subject, subjection. In: C. Paechter, M. Preedy, D. Scott and J. Soler, Eds., Knowledge, Power and Learning, Sage, Thousands.

[14] Hiemstra, R. (1976) Lifelong learning. Professional Educators Publications, Inc., Lincoln.

[15] Knowles, M.S. (1970) The modern practice of adult education. Associated Press, New York.

[16] Terry, M. (2006) Self-directed learning by undereducated adults. Educational Research Quarterly, 29, 28-38.

[17] Knox, A.B. (1986) Helping adults learn: A guide to planning, implementing, and conducting programs. JosseyBass, San Francisco.
[18] Borg, W.R. and Gall, M.D. (1989) Educational research: An introduction. Longman, New York, 782-804.

[19] Johnson, S.R. and Johnson, R.B. (1970) Developing individualized instructional material: A self-instructional material in itself. Westinghouse Learning Press, California.

[20] Knowles, M.S. (1975) Self-directed learning: A guide for learners and teacher. Associated Press, Chicago.

[21] Mager, R.F. (1984) Preparing instructional objectives. 2nd Edition, Pitman Learning, Belmont.

[22] Race, P. (1992) 53 Interesting ways to write open learning materials. Billings \& Sons, Ltd., Worcester.

[23] Rowntree, D. (1990) Teaching through self-instruction: How to develop open learning materials (Rev.ed.). Nichols Publishing, New York.

[24] Alberta Association of Registered Nurses (2006) Membership. http://www.nurses.ab.ca/about/membership.html

[25] Allen, D. (2005) Healthy solutions. Alberta RN, 61, 1719. 